
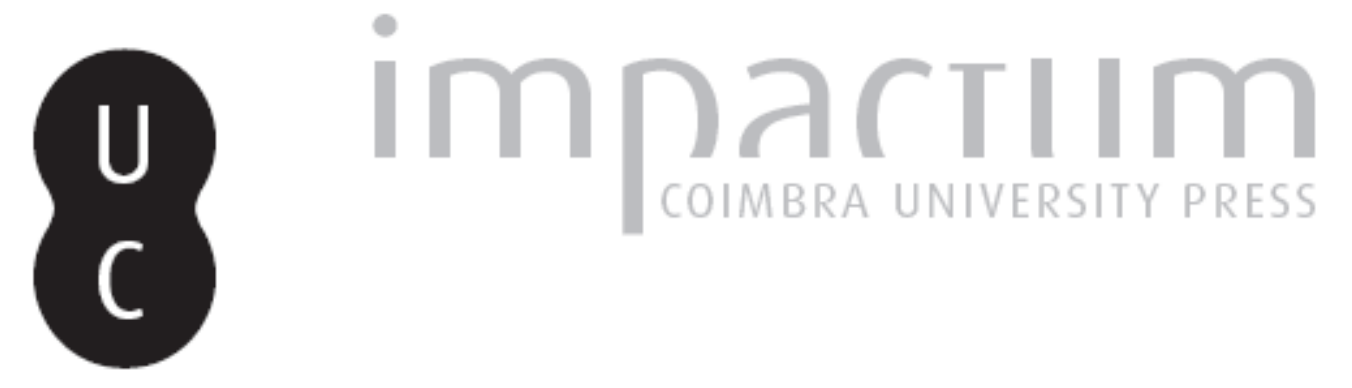

\title{
Vier singulare römische Skulpturen aus Portugal
}

Autor(es): $\quad$ Souza, Vasco de

Publicado por: Imprensa da Universidade de Coimbra

URL persistente:

URI:http://hdl.handle.net/10316.2/45654

DOI:

DOI:https://dx.doi.org/10.14195/1647-8657_24_3

Accessed : $\quad$ 26-Apr-2023 12:41:04

A navegação consulta e descarregamento dos títulos inseridos nas Bibliotecas Digitais UC Digitalis, UC Pombalina e UC Impactum, pressupõem a aceitação plena e sem reservas dos Termos e Condições de Uso destas Bibliotecas Digitais, disponíveis em https://digitalis.uc.pt/pt-pt/termos.

Conforme exposto nos referidos Termos e Condições de Uso, o descarregamento de títulos de acesso restrito requer uma licença válida de autorização devendo o utilizador aceder ao(s) documento(s) a partir de um endereço de IP da instituição detentora da supramencionada licença.

Ao utilizador é apenas permitido o descarregamento para uso pessoal, pelo que o emprego do(s) título(s) descarregado(s) para outro fim, designadamente comercial, carece de autorização do respetivo autor ou editor da obra.

Na medida em que todas as obras da UC Digitalis se encontram protegidas pelo Código do Direito de Autor e Direitos Conexos e demais legislação aplicável, toda a cópia, parcial ou total, deste documento, nos casos em que é legalmente admitida, deverá conter ou fazer-se acompanhar por este aviso.

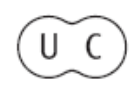


FACULDADE DE LETRAS

INSTITUTO DE ARQUEOLOGIA

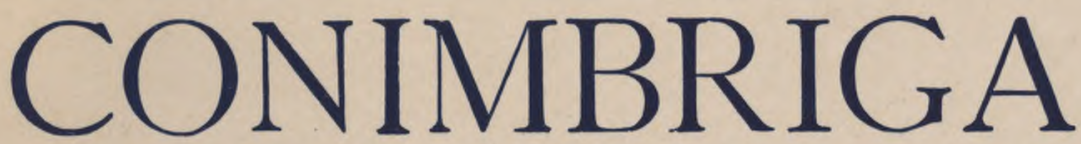

VOLUMEXXIV

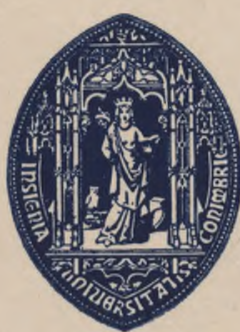

UNIVERSIDADE DE COIMBRA

1985 
VASCO DE SOUZA

Investigador

VIER SINGULÂRE ROMISCHE SKULPTUREN AUS PORTUGAL «Conimbriga», XXIV (1985), p. 97-104

Resumo: o busto feminino, sem cabeça, existente no Museu de Beja, sem indicação de proveniência, apresenta-se vestido com túnica e manto pelos ombros. O apoio com decoração vegetal parece, indicar tratar-se de um retrato de mulher falecida. Data da época de Cláudio.

A estatueta do Museu Nacional de Arqueologia e Etnologia de Lisboa, procedente de Balsa, deve interpretar-se como Fortuna-Spes, em virtude do trajo arcaico (Spes) e da proa do navio (Fortuna). A estatueta data provavelmente do início da era imperial.

A estátua couraçada e com paludamentum de Manizola (Évora) é digna de nota pela decoração central da couraça: não se encontram, noutras estátuas couraçadas, grifos a flanquearem um vaso. $\mathrm{O}$ friso de armas entre a orla da couraça e o pteryges faz pensar na época de Trajano como data provável da estátua.

$\mathrm{Na}$ tampa do sarcófago de Lisboa, com 2,26 m de comprimento, pode ver-se na metade direita a representação de um banquete sigmático com três participantes. A representação da metade esquerda da tampa pode ser interpretada como cena de caça. A peça pode atribuir-se à época de Galieno.

RESÜMEE: Die kopflose weibliche Büste in Beja ist mit Tunika und über die Schultern gelegtem Mantel bekleidet. Die pflanzlich ausgestaltete Innenstütze spricht für ein Weibliches Verstorbenenbildnis. Das Exemplar ist in claudischer Zeit entstanden. Die Deutung der Statuette in Lissabon als Fortuna-Spes ergibt sich aus der archaistischen Tracht (Spes) und dem Schiffsbug (Fortuna). Die Statuette diirfte in die frühe Kaiserzeit zu datieren sein.

Die Panzerstatue mit Paludamentum in Manizola (Évora) ist wegen der Hauptdekoration des Panzers auffallend: Greifen, die ein Gefafl flankieren, kommen sonst an den Panzerstatuen nicht vor. Der Waffenfries zwischen Panzerrand und dem Pteryges legt eine Datierung der Statue in trajanische Zeit nabe.

Bei dem 2,26 m langen Sarkophagdekcel in Lissabon sieht man in der rechten Halite die Darstellung eines Sigmamahls mit drei Teilnehmern. Die Darstellung in der linken Deckelhálfte kann ais Jagdszene gedeutet werden. Das Stiick diirfte in gallienischer Zeit entstanden sein. 
(Página deixada propositadamente em branco) 


\section{VIER SINGULARE RÖMISCHE SKULPTUREN AUS PORTUGAL}

Kopflose weibliche Büste

Taf. 1 und 2

Das Stück, dessen Provenienz unbekannt ist, befindet sich ohne Inventarnummer im Museu Regional de Beja. Das Material ist Marmor, die Höhe beträgt 0,31 m. Es fehlt der Kopf, die Oberfläche zeigt Sinterspuren.

Bekleidet ist die Büste mit Tunika und über die Schultern gelegtem Mantel. Die Falten des Ober- und Untergewandes werden durch tiefe Bohrkanäle voneinander getrennt. Der Zapfen unter der Büste diente zur Montierung derselben auf einem Sockel. Die pflanzlich ausgestaltete Innenstütze hat die Form eines Pilasterkapitells mit Akanthus und Rosetten, das aber nicht vollständig ausgearbeitet ist. In seinem Werk über das Bildnis im Blätterkelch führt $H$. Jucker fünf männliche Büsten an, darunter eine Trajans, deren Innenstützen eine vegetabilische Dekoration aufweisen (1). Im Rahmen der Interpretation dieses Autors würde es sich bei unserer Büste um die Darstellung einer Verstorbenen handeln $\left({ }^{2}\right)$. Eine Datierung des Exemplars in Beja in claudische Zeit ergibt sich aus dem Vergleich der Gewandfalten, besonders der Mantelfalten auf der linken Schulter mit denen der Agrippina Minor aus Milreu in Faro (3). Auch die Büstenform spricht für diesen Zeitansatz.

Statuette der Fortuna-Spes

Taf. 3

Die Statuette mit der Inventarnummer 17944 befindet sich im Museu Nacional de Arqueologia e Etnologia zu Lissabon.

(r) H. JuCKer, Das Bildnis im Blätterkelch (1961) 129 St 22, St 29, St Anhang 1, 2, Abb. 11.

(2) JUCKER, a.O. 133 ff.

(3) W. твillmich, MM 15, 1974 Taf. 35.36.

Conimbriga, 24 (1985), 97-104 
Gefunden wurde sie auf der Quinta das Antas, Balsa (Algarve), ihre Höhe beträgt $0,42 \mathrm{~m}$, das Material ist Marmor. Es fehlen der Kopf und beide Unterarme. Bruchstelle neben dem linken Oberschenkel, Riß am rechten Rand der Basis. Auch sonst kleine Beschädigungen. Das Stück wurde mit Säure gereinigt.

Auf einer rundlichen Basis steht die Göttin auf dem rechten Fuß, den linken setzt sie auf ein Schiffsvorderteil. Der Oberkörper zeigt eine leichte Torsion nach links. Bekleidet ist sie mit einem Chiton und einem Peplos mit Überschlag. Die dicke diagonale Gewandfalte über der Brust stellt den gedrehten Peplossaum dar. Die Deutung der Figur als Fortuna-Spes geht aus dem Schiffsvorderteil und der archaistischen Tracht hervor. $\mathrm{Zu}$ den Attributen der Glücksgöttin zählt neben dem Steuerruder, dem Globus, dem Füllhorn - um nur die wichtigsten zu nennen - auch das Schiffsvorderteil (*). Archaistische Tracht, das Motiv des Gewandraffens mit der einem Hand und die Blüte in der anderen charakterisieren die Darstellungen der Spes $\left.{ }^{(}\right)$. Kommt es zu einer Verbindung der beiden Gottheiten $\left(^{3}\right)$, so trägt die Fortuna die Tracht der Spes und faßt mit einer Hand das Gewand. Die Bruchstelle neben dem linken Obserschenkel unserer Statuette ist ein sicheres Indiz für das Motiv des Gewandraffens. Durch diesen Gestus erklärt sich auch die Oberkörpertorsion. Was sie in der Rechten hielt, ist nicht mehr auszumachen. Bei zwei Marmorstatuen der Fortuna-Spes in Dresden $\left({ }^{4}\right)$ und München $\left({ }^{5}\right)$ wird mit einer Hand das Gewand gerafft und der anderen ein Füllhorn gehalten.

Datierung: Frühe Kaiserzeit.

Lit.: J. LeITe de Vasconcelos, Religiões da Lusitânia III (1913) 512 f. Abb. 275. - Reinach, RSt V 382, 1.

(1) EAA III (1960) 726 f. s.v. Fortuna (Floriani-Squarciapino).

$\left({ }^{2}\right)$ Roscher, ML IV 1295 ff. s.v. Spes (Wissowa).

(3) Belege für diese Verbindungen bei Roscher, ML I 2, 1537 ff. s.v. Fortuna (R. Peter).

$\left.{ }^{4}\right)$ H. Hettner, Die Bildwerke der königlichen Antikensammlung zu Dresden (1881) 55 Nr. 12.

(5) A. Furtwängler, Beschreibung der Glyptothek zu München (1910) 54 f. $\mathrm{Nr} 49$.

Conimbriga, 24 (1985), 97*104 
Torso einer Panzer statue in der Herdade de Manizola (Évora)*

Taf. 4

An der Straße von Évora nach Arraiolos, ca. zwei Kilometer von Évora entfernt, liegt die Herdade de Manizola. Links an der Eingangstreppe des Hauptgebäudes befindet sich der Torso einer Panzerstatue, der um die Jahrhundertwende in der Herdade Sempre Noiva (Alentejo) gefunden wurde. Die Höhe des Torsos beträgt 1,17 m, das Material ist Marmor. Es fehlen der zum Einsetzen gearbeitete Kopf, die Beine bis auf einen Teil der Oberschenkel und Teile des linken Ober- und Unterarmes. Abgeschlagen ist der ganze rechte Rand der Statue, ein Teil der rechten Schulter sowie die seitliche Partie des linken Oberschenkels. Die Oberfläche ist bestoßen und verrieben, die Rückseite vernachlässigt. Der Halsausschnitt ist oval. Die höhersitzende und heraustretende linke Hüfte sowie die schräg angegebenen Laschen am rechten Oberschenkel lassen auf ein linkes Standbein und rechtes Spielbein schließen. Die Lederstreifen am linken Arm enden in Fransen. Unter den Fransen sieht man noch einen Teil der Tunika. Das über die linke Schulter geworfene Paludamentum bedeckt einen Teil der Brust, fällt senkrecht am Rücken herab und war unten von dem linken Arm aufgenommen. An der Brust des Panzers ist ein geflügelter Medusenkopf mit unter dem Kinn geknoteten Schlangen dargestellt. Die Mitte des Panzers nimmt eine heraldische Komposition ein: ein Kantharos, dem eine Lotusblüte entwächst, wird von zwei antithetischen Greifen flankiert, die ihre erhobene innere Vordertatze an das Gefäß legen. Diese Fabeltiere stehen auf kräftigen Trieben, die aus einem Akanthuskelch wachsen. An den Enden der Triebe bilden sich Rosetten. Der Torso weist zwei Pterygesreihen auf. Von der Dekoration der oberen Reihe erkennt man nur einen bärtigen Männerkopf und Doppelwidderköpfe. Die untere Reihe ist ohne Schmuck. Zwischen dem Panzerrand und dem Pteryges läuft ein Waffenfries.

* Für die freundliche Erlaubnis, den Torso untersuchen zu dürfen, hab iche den Besitzern der Quinta de Manizola, Familie Barahona, zu danken. 
Das Thema des von Greifen flankierten Gefäßes kommt z.B. auf einem architektonischen Fries des Trajansforums G), den Campanareliefs $\left(^{2}\right)$ und im Bereich der Sepulkralkunst $\left(^{3}\right)$ vor. Auf einer Panzerstatue ist es jedoch singulär. Mir ist kein zweites Beispiel bekannt. Das Gefäß mit der Pflanze symbolisiert das wohltätige, reinigende, befruchtende und lebensspendende Wasser $\left({ }^{4}\right)$. Die flankierenden Greifen sind als Hüter der Vase zu verstehen $\left({ }^{5}\right)$.

Die künstlerische Qualität der Reliefs ist bescheiden. Es handelt sich wohl um eine Arbeit lokaler Provenienz.

Die Zeitstellung des Manizolatorsos ergibt sich aus dem Waffenfries. Im Museo Arqueológico Provincial von Sevilla befinden sich ein Torso aus Itálica und eine linke Torsohälfte aus Alcalá del Rio, die mit ihren Waffenfriesen zwischen dem Panzerrand und den Pteryges die nächsten Parallelen zu unserem Exemplar bilden. Für die Stücke in Sevilla hat man allgemein eine Datierung in trajanische Zeit erwogen $\left(^{6}\right)$. Der Torso in Manizola dürfte in derselben Zeit entstanden sein.

(1) Ch. F. Leon, Die Bauornamentik des Trajansforums und ihre Stellung in der früh- und mittelkaiserlichen Architekturdekoration Roms (1971) 68 Taf. 11,$2 ; 12,2-3$.

(2) A. H воввегn, Campanareliefs. Typologische und stilkritische Untersuchungen, RM.EH. 14, 1968, 97 if.

(3) I. F LAGGE, Untersuchungen zur Bedeutung des Greifen (1975) 94 ff.

(4) H. Juc кеR, Das Bildnis im Blätterkelch (1961) 175.

(5) FLAGGE a.a.O. $96 \mathrm{f}$.

$\left.{ }^{6}\right)$ Torso Itálica mit trajanischer Datierung: C. Vermeule, «Berytus» 13, 1959/60 Nr. 127; García y Bellido, Colonia Aelia Augusta Italica (1960) 153 f. Nr. 21 Taf. 45; H. Оенцев, Untersuchungen zu den männlichen römischen Mantelstatuen. Der Schulterbauschtypus (1961) 71; K. Sтеммег, Untersuchungen zur Typologie, Chronologie und Ikonographie der Panzer Statuen, AF4 (1978) 113 f. XI 4 Taf. 77, 1-3. Torso Alcalá del Rio mit trajanischer Datierung: A. Balil, «Zephyrus», 12, 1961, 206 f. Nr. 8; Sтеммев a.a.O. 104 VIII 12 Taf. 71,4. Acuna Fernandez, Esculturas Militares Romanas de Espana y Portugal (1975) 35'ff. Nr. 1 Abb. 1 (Alcalá del Rio) und 63 ff. Nr. 9 Abb. 35.36 (Itálica) datiert die Stücke in Sevilla in julisch-claudische Zeit. 
Fragmente eines Sarkophagdeckels

Im Museu Nacional de Arqueologia e Etnologia zu Lissabon befindet sich ohne Inventarnummer ein aus zehn Fragmenten zusammengesetzter Sarkophagdeckel. Gefunden wurden die Fragmente in Tróia, Setúbal, während der Grabungskampagnen von 1968 und 1969. Das Material ist Marmor. Die Höhe des Deckels beträgt $0,36 \mathrm{~m}$, die Länge $2,26 \mathrm{~m}$ und die Tiefe $0,36 \mathrm{~m}$. In der Mitte inschriftlose Tabula. Unbärtige Barbarenköpfe mit phrygischer Mütze als Eckakrotere $\left({ }^{x}\right)$. In der rechten Deckelhälfte Darstellung eines Sigmamahls $\left({ }^{2}\right)$ mit drei Teilnehmern, die mit einer tunica exomis bekleidet sind, im Hintergrund ein Arkadengebäude, vor dem Polster ein Eberkopf auf einer Schüssel und drei Brote. Von links nach rechts: Reste eines Baumes und Reste eines nach rechts eilenden Dieners (mit Stiefeln bekleidete Füße). Es folgen dann die Symposiumteilnehmer. Der Linke, mit übereinandergeschlagenen Beinen, lehnt sich an das Sigma. In der Linken hält er den Becher, während er mit der Rechten auf die Speise weist. Vor ihm, auf dem Polster, liegt als Requisit des Gelages eine Handgirlande ( $\left.{ }^{3}\right)$. Der Mittlere - älter als die anderen zwei Symposiasten - zeichnet sich durch eine würdige Haltung aus. Er ist bärtig dargestellt. In der Linken hat er den Becher, die Rechte ist um das Polster gelegt. Der Teilnehmer ganz rechts hält in der Linken den Weinschlauch und ruft mit der erhobenen Rechten nach dem Diener.

In der linken Deckelhälfte wohl eine Szene aus dem Bereich der Jagd. Von links nach rechts: eine Mondsichel, die darauf hindeutet, daß die Szene in der Nacht stattfindet. Darunter eine Gruppe, bestehend aus einem Mann mit einem Kentron in der erhobenen Rechten und einem vorn niederknienden Hund. Es folgen zwei sitzende Männer (Kutscher und Beifahrer) auf einem

0) T. Brennecke, Kopf und Maske (Diss. Berlin 1970) $47 \mathrm{ff}$.

(2) F. Gerke, Die christlichen Sarkophage der vorkonstantinischen Zeit (1940) 110 ff. N. Himmelmann, Typologische Untersuchungen an römischen Sarkophagreliefs des 3. und 4. Jahrhunderts n. Ghr. (1973) 24 ff. (mit einer Zusammenstellung von Sigmamahldeckeln).

(3) H. sic t termann, Späte Endymion-Sarkophage (1966) $21 \mathrm{ff}$. 
von Ochsen gezogenen Plaustrum mit Scheibenrad. Der Kutscher treibt mit dem Kentron die Ochsen an. Der Beifahrer wendet sich zu dem Mann mit dem Hund zurück und scheint ihm etwas mitzuteilen. Auf dem Schoß hat er einen nicht genau zu erkennenden Gegenstand. Alle drei Männer sind mit der Tunika bekleidet und tragen eine Kapuze. Zwischen beiden Gruppen ein Baum.

Vor dem Wagen ein weitaufgespanntes Netz, das an einem zweiten Baum festgemacht ist. In diesem Netz hat sich ein Panther verfangen. $\mathrm{Zu}$ dieser Jagdszene ist mir keine genaue Parallele bekannt, doch gibt es andere Sarkophagdeckel, die eine Zusammenstellung von Sigmamahl und Jagddarstellung zeigen $\left({ }^{4}\right)$. Bohrkanäle an dem Haar der Barbarenköpfe. Runde Bohrlöcher an den Augen, Mundwinkeln, Nasen der Figuren und auch an dem Bart des mittleren Symposiumteilnehmers.

Die Zeitstellung des Deckels in Lissabon in das dritte Viertel des 3.Jhs. wird durch den Vergleich des Barbarenkopfes mit dem linken Eckkopf am Deckel des in gallienische Zeit datierten Bellerophonsarkophages in Algier nahegelegt $\left(^{5}\right)$. Ähnlich ist die Anlage des Haares und dessen Bohrstil, die Gestaltung des geöffneten Mundes, die breite Nase mit abgesetzten Nasenflügeln, die Bildung der Augen sowie das runde, leicht vorgeschobene Kinn.

Lit.: J. Alarcão, Portugal Romano (1974) 203 f. Abb. 51.

(4) B. ANDREAE, ASR I 2, $102 \mathrm{f}$.

(5) G. Косh-H. Sichtermann, Römische Sarkophage (1982) 143 Abb. 15.4 
TAF. I

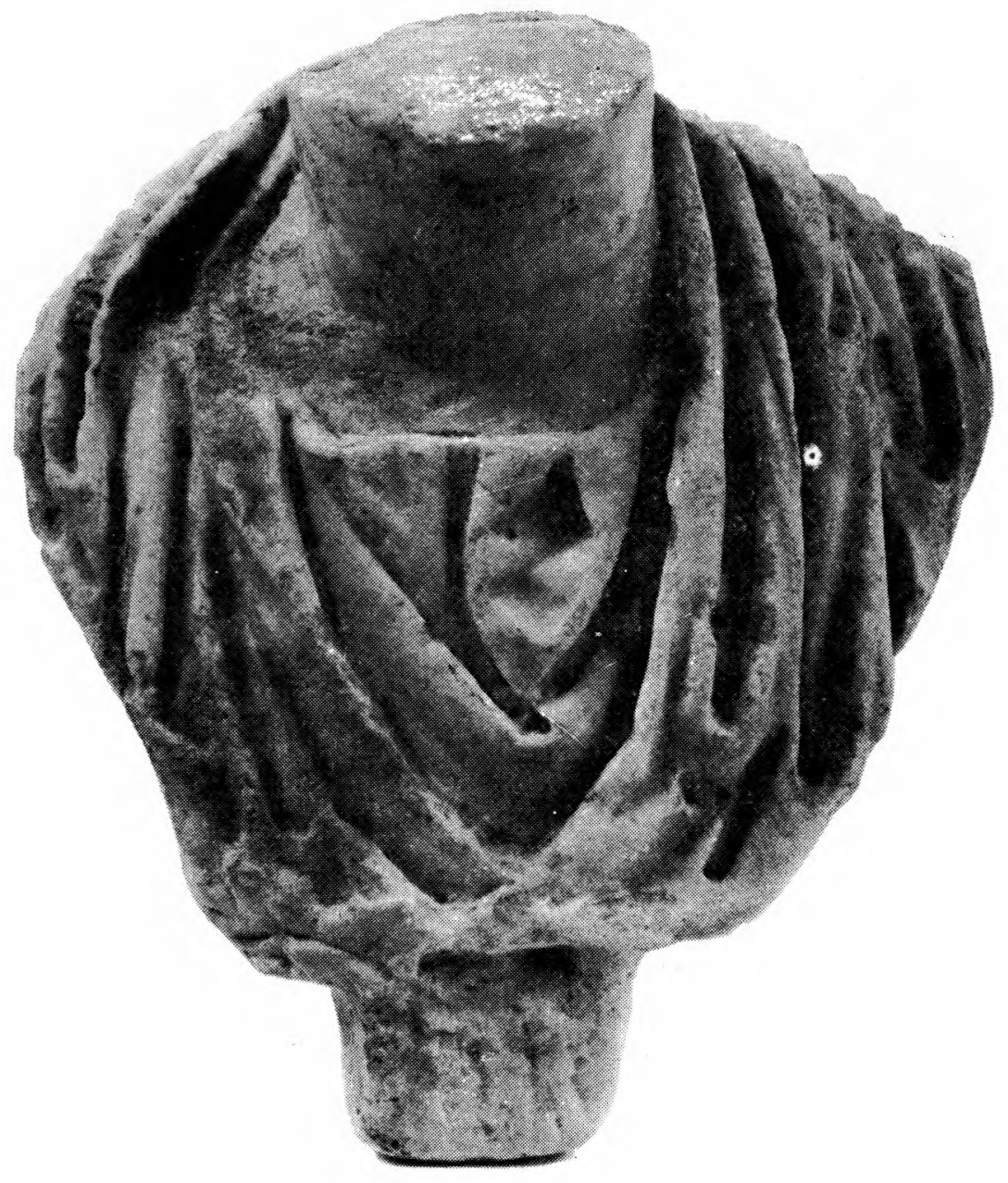


TAF. 2

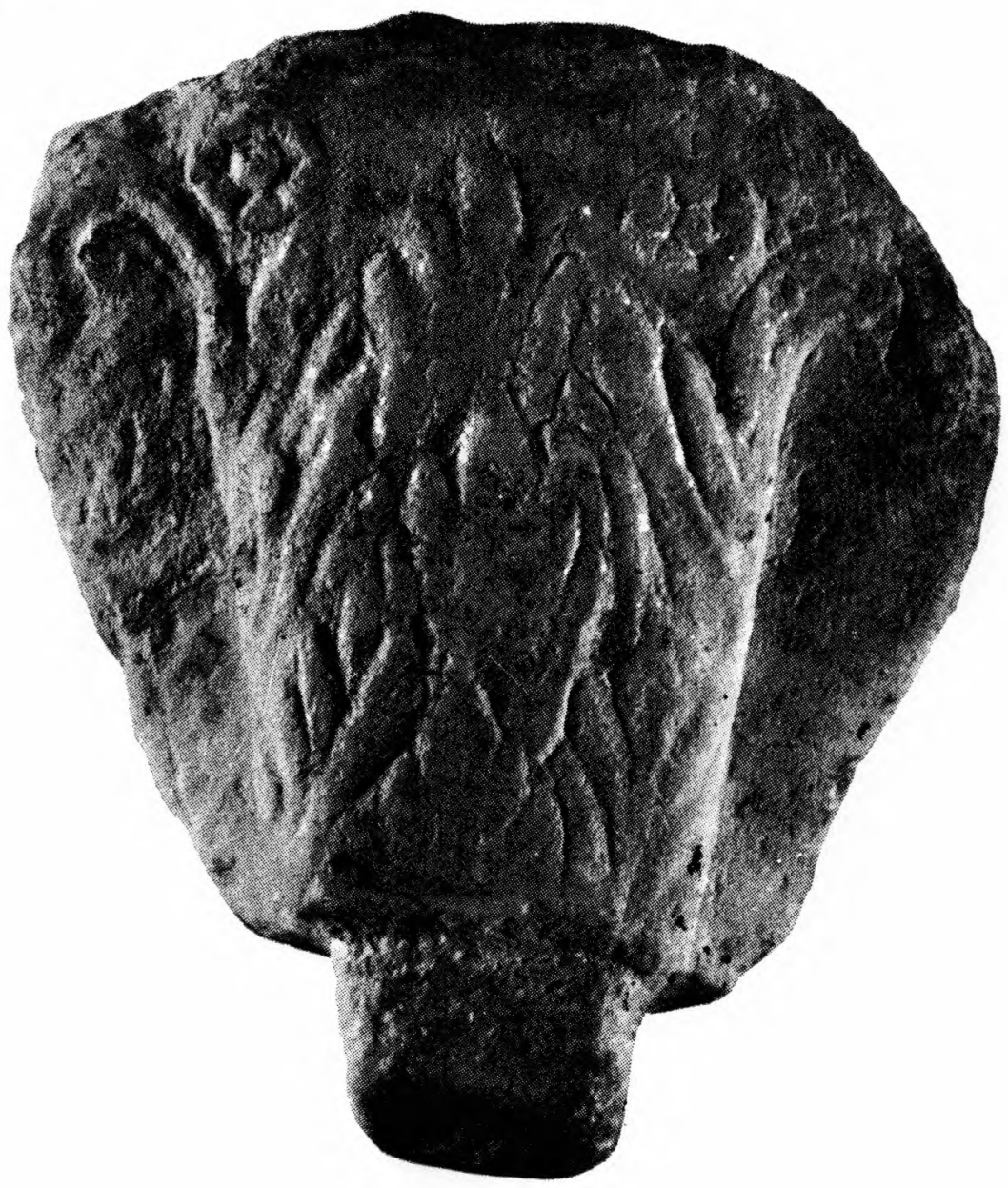


TAF. 3

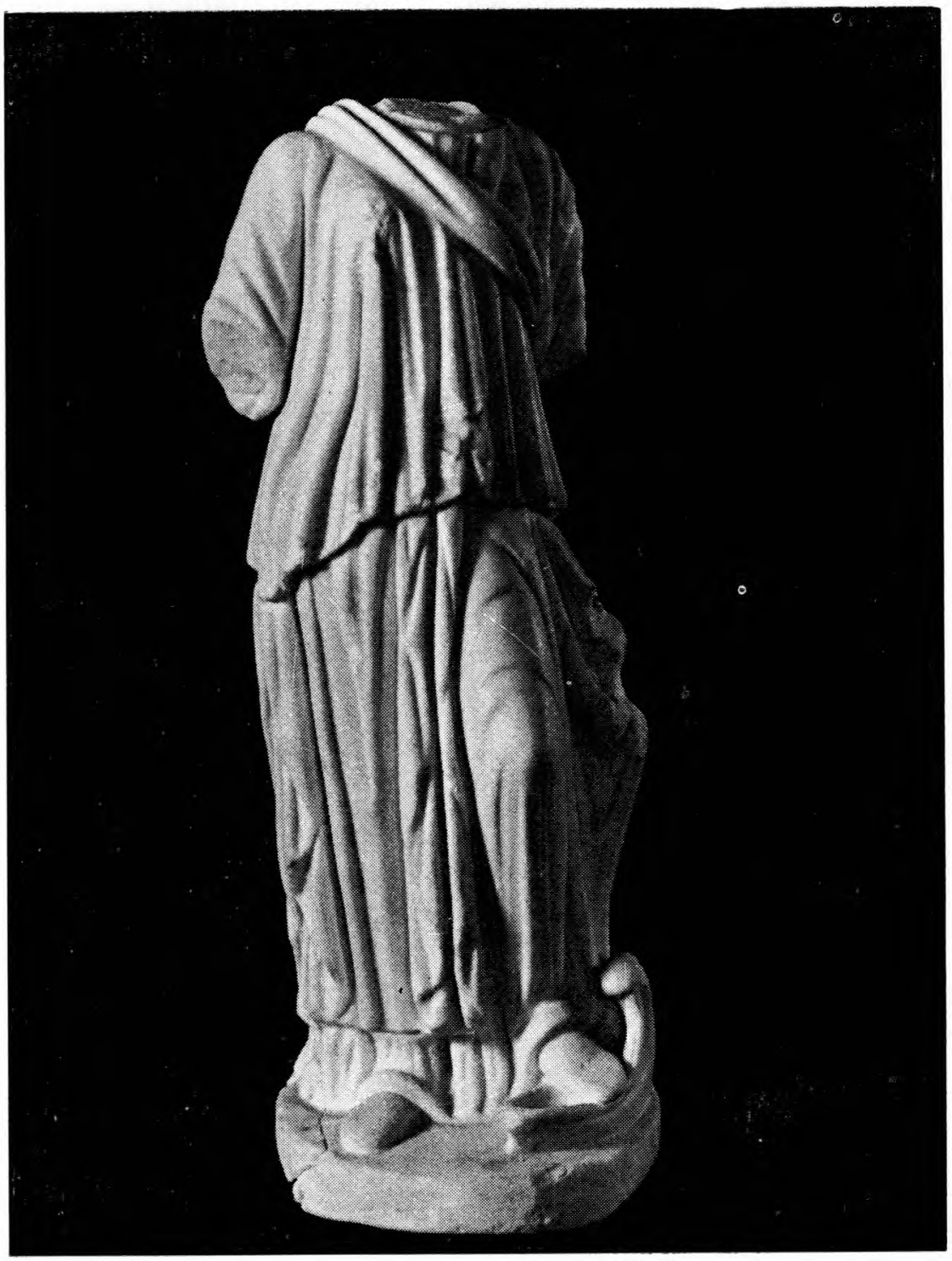


TAF. 4

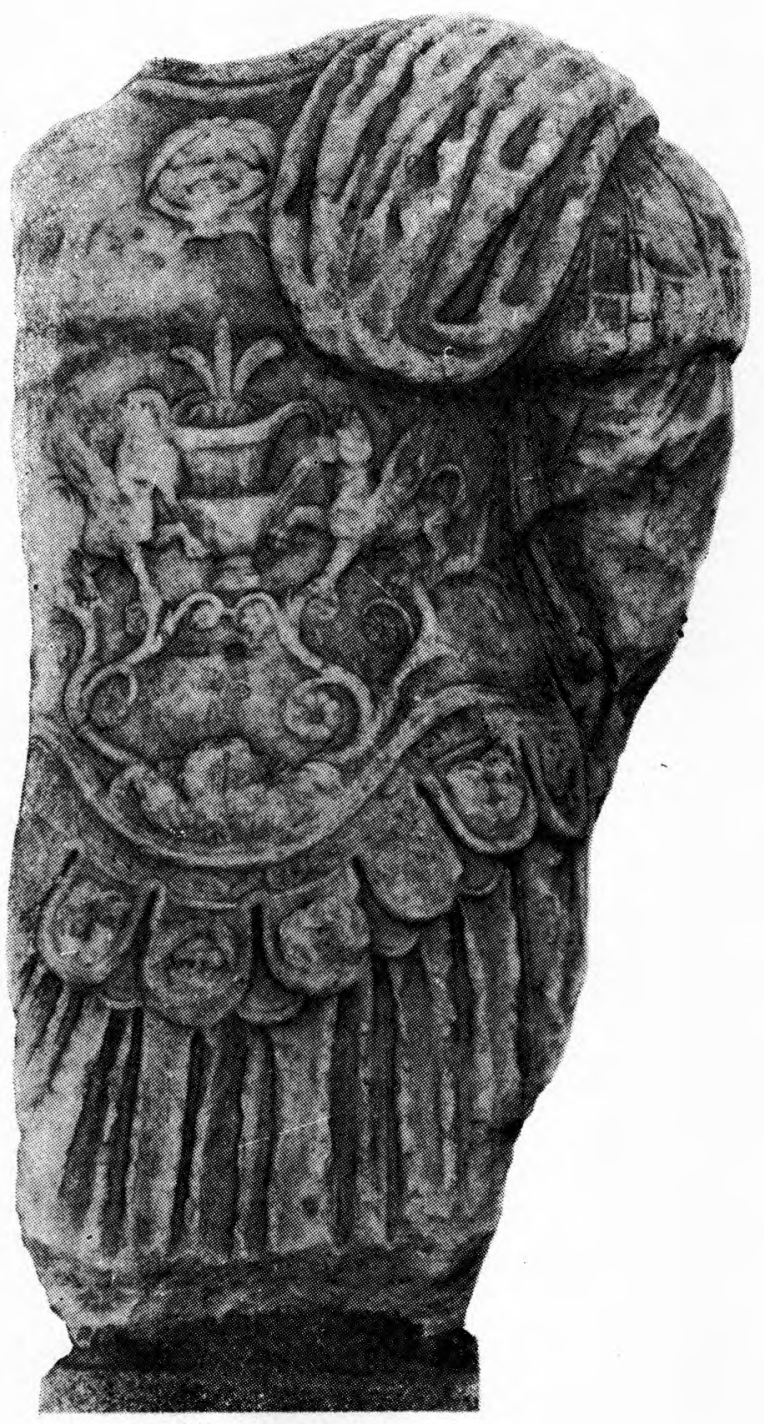


TAF. 5

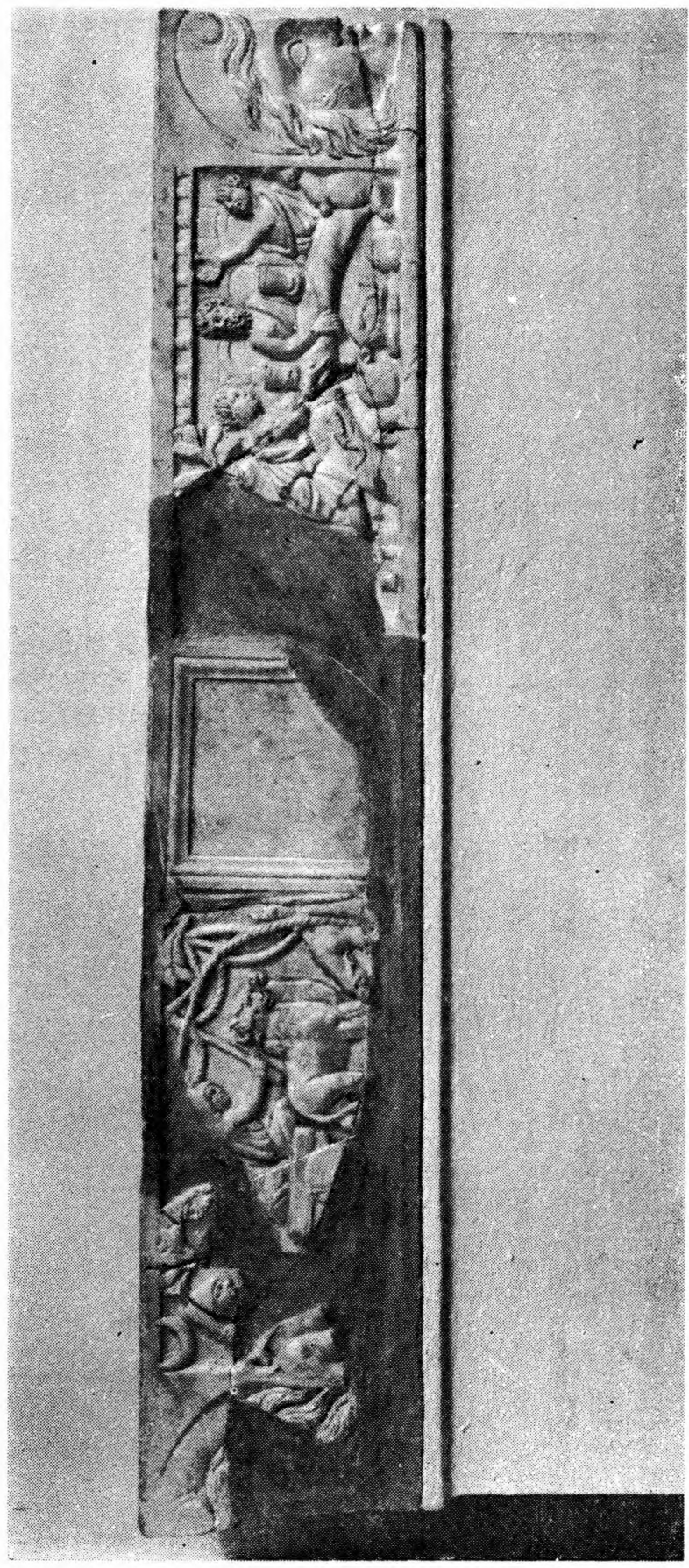

